\title{
The Non-Technical Challenges of Location Based Services Markets: Are the Users' Concerns Being Ignored?
}

\author{
Anahid Basiri \\ The Nottingham Geospatial Institute \\ The University of Nottingham \\ Nottingham, UK \\ Anahid.Basiri@nottingham.ac.uk \\ Terry Moore \\ The Nottingham Geospatial Institute \\ The University of Nottingham \\ Nottingham, UK \\ Terry.Moore@,nottingham.ac.uk
}

\author{
Chris Hill \\ The Nottingham Geospatial Institute \\ The University of Nottingham \\ Nottingham, UK \\ Chris.Hill@,nottingham.ac.uk \\ Paul Bhatia \\ The Nottingham Geospatial Institute \\ The University of Nottingham \\ Nottingham, UK \\ Paul.Bhatia@nottingham.ac.uk
}

\begin{abstract}
Location Based Services (LBS) market is growing rapidly, however it has faced several challenges and issues, including the availability of reliable positioning services seamlessly (indoors and outdoors), the privacy protection issues, and the relatively high demands for resources, such as high power consumption and cost. Among all the issues introduced to the markets of LBS, the non-technical issues can be easier to understand for many of ordinary users of LBS and they, consequently, can become yet bigger challenge to the development of LBS markets. Lack of social acceptance of the LBS applications can result in slowing down the growth of the market, if not failure. This paper reviews the non-technical issues of LBS market from users' perspective and evaluate the significance of their impact on the growth of the market based on the results of a survey conducted and the predictive analysis have been done.
\end{abstract}

Keywords-Location Based Services (LBS); non-technical challenges; privacy; social acceptance.

\section{INTRODUCTION}

Location Based Services market is growing rapidly, several market reports and research paper study the LBS market growth [1-5] and they estimate the LBS market to grow with a minimum $35.2 \%$ CAGR during the 2016-2020, this growth can generate up to USD 54.95 billion revenue by 2020 . However this growth has faced several challenges and obstacles, including the availability of accurate positioning technologies especially for indoor use [6-7], cost of the service, location privacy issues [8], high power consumption [9], and the user interface of the apps. Some of these challenges are not directly linked to the technology; such "non-technical" challenges, requirements and issues seem to be easier to handle or solved and having a better understanding of them can help the policy makers, manufacturers, service providers and developers to take actions on them and help the LBS markets to grow with a higher growth rate, attracting more users. Also non-technical issues are easier to recognise by many ordinary LBS users and this potentially result in overestimation of the threats and effects, which can introduce a big challenge to the development of the mass market. A study of IT "abandonment" reported by the British Computer Society (BCS) reinforces the notion that IT projects fail primarily for non-technical causes. Privacy and the business models have been ranked as the most important reasons of failing LBS apps [3, 10-11] and neither is technological reason. This paper reviews the non-technical requirements of successful LBS applications.

Some of the ethical, social and personal dilemmas of mobile users when using/downloading mobile applications are already reviewed by [12-13]. Having a better understanding of the complexities, multiple interests and contextual factors, mostly non-technical, which must be incorporated into the examination of mobile applications.

To have a better understanding of the importance of challenges, which LBS applications face, a survey conducted targeting ordinary and non-expert users of LBS, LBS app developers, companies and industry providing components of LBS (such as antennas and wireless networks), and researchers and market analysts working on the LBS markets. The results of the survey are discussed in the second section. This is followed by a short review on available solutions and approaches to handle the identified challenges and a list of suggestions and potential solutions.

\section{CHALLENGES OF LBS FROM NON-TECHNICAL PERSPECTIVE}

Non-technical challenges refer to the issues that are not relating to or involving science or technology, such as social acceptance, commercialization and business models, privacy concerns, human factors, and cultural differences [8,9]. This paper considers the "non-technical" issues and challenges as those challenges, which are not directly technical or scientific. 
However this does not mean that technology cannot be an answer to such challenges. On the other hand, some of the nontechnical challenges might have been introduced due to technological limitations. For example privacy concerns can have some roots in the positioning technology and the security of the network, which might be addressed using some anonymity algorithms, i.e. technical answer. Such roots might not be fully understandable to an ordinary user of LBS application who has not been trained in computer science, mobile programing, positioning and tracking, etc. Therefore, when it comes to non-technical the users' point of view, the opinion of the end users can be very important.

In order to understand the non-technical challenges of the location-based services applications, a survey is conducted. This survey has been open since May 2015, having had 130 participants, aged between 18 to 73 , both male and female, from several sectors and with different educational backgrounds; the distribution of the expertise (related to LBS) of 106 participants (out of 130 total participants) who answered all the questions of the survey and also specified their level of expertise, is shown in table 1.

\begin{tabular}{|c|c|}
\hline Participants Group & Percentage \\
\hline $\begin{array}{l}\text { LBS users } \\
\text { (who only use LBS applications, devices and/or } \\
\text { services in daily life) }\end{array}$ & $54.72 \%$ \\
\hline $\begin{array}{l}\text { LBS application developers } \\
\text { (who design, develop, or deploy LBS } \\
\text { applications/services) }\end{array}$ & $9.43 \%$ \\
\hline $\begin{array}{l}\text { LBS content providers } \\
\text { (who provide content and/or information, such as } \\
\text { map, points of interest and advertisements, to be } \\
\text { delivered through LBS applications and/or services) }\end{array}$ & $1.89 \%$ \\
\hline $\begin{array}{l}\text { LBS components company } \\
\text { (who produce LBS components, such as antennas, } \\
\text { receivers, transmitters) }\end{array}$ & $0.00 \%$ \\
\hline $\begin{array}{l}\text { LBS researcher and LBS market analyst } \\
\text { (who studies LBS and related technologies, } \\
\text { applications, markets) }\end{array}$ & $26.42 \%$ \\
\hline Other & $7.55 \%$ \\
\hline
\end{tabular}

Table I. The categories of the participants in the survey and their distribution

As it shown in table 1 , more than half $(54.72 \%)$ of the participants identified themselves as "LBS users", who only use LBS applications, devices and service in daily life. Due to having majority of the responses from this group of participants and also minimising the impact of technical roots in prioritisation of the challenges, this paper reflects the views of the ordinary users of LBS. However the differences and the gap between the views of other participants and the users' will be discussed, in more details, in the next section as it is one of the key issues of the current markets of LBS.
$52.63 \%$ of the users (i.e. 20 participants) have three or four devices with positioning capabilities, such as mobile phone, Satnavs, fitness devices, iWatch, iPod, iPad, in vehicle navigation devices). 22 participants have one or two, and only $5.25 \%$ (i.e. 2 participants) have 7-8 devices and use it routinely. More than a quarter of the participants use their devices once a day and almost one fifth $(21.05 \%)$ use them 2-5 times (see figure 1).

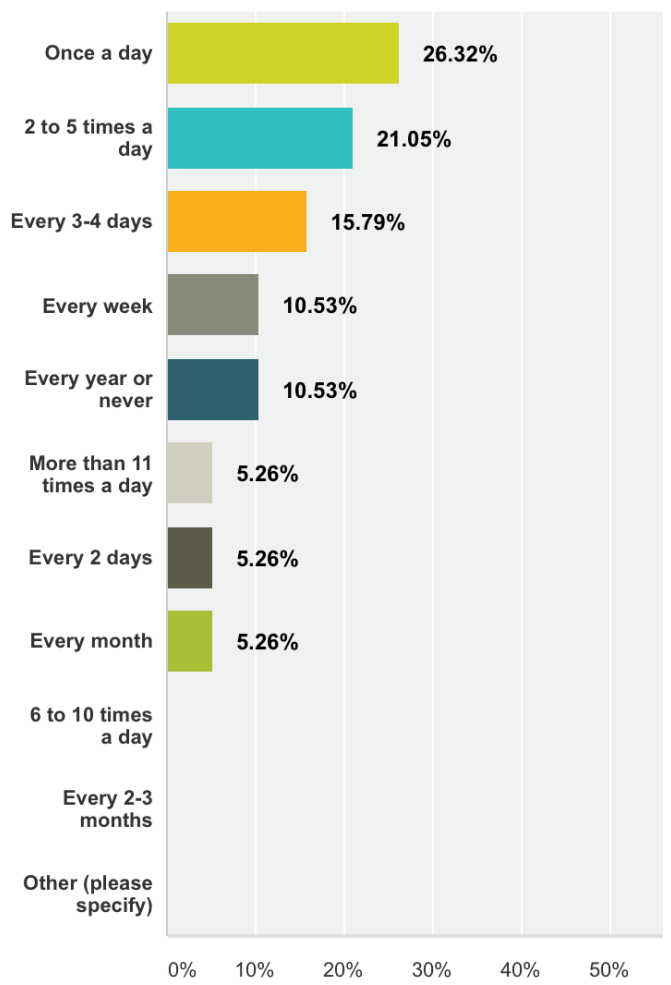

Fig. 1. The frequency of use of the location-enabled devices

The most important features of an location-enabled device, such as satnav or mobile phone, is size of the device, cost, size of the screen, weight of the device, and user interface, which all can be considered as not-technological factors, see figure 2 . There are some factors to do with the quality of the positioning services, including accuracy and continuity, but they all come after size, weight and other design-related parameters. As it is shown in figure 2, privacy and battery life are not the major concerns of the users when they buy a new device, however these become more important when the user download and use an LBS app.

When it comes to the LBS apps (rather than the device), it seems that the frequency of use is much higher; more than double percentage; i.e. $44.44 \%$ of the participants use LBS apps 2-5 times a day, see figure 3 .

The participants were asked to rank the least to the most important features of an LBS application. The available features included power consumption, user-friendly interface, price of the first purchase, subscription or update fee, privacy and cost of supporting technology. The results surprisingly show that the subscription fees, price of the first purchase, and the update fee, are the least important features when users 
decide to download or use an LBS app. While the cost of the supporting technology, such as buying a new device or modification of their mobile phone to support the app, are the most important features. This shows that users do consider financial implications; however when it is not permanently change the hardware they are more willing to pay. Also it might be due to the fact that amount of money to be paid for app purchases or subscription/update are relatively lower than device modification and/or purchase. The hardware purchase cost is not at interest of this paper, and this paper is only focuses on the non-technical factors of an LBS app rather than device or hardware.

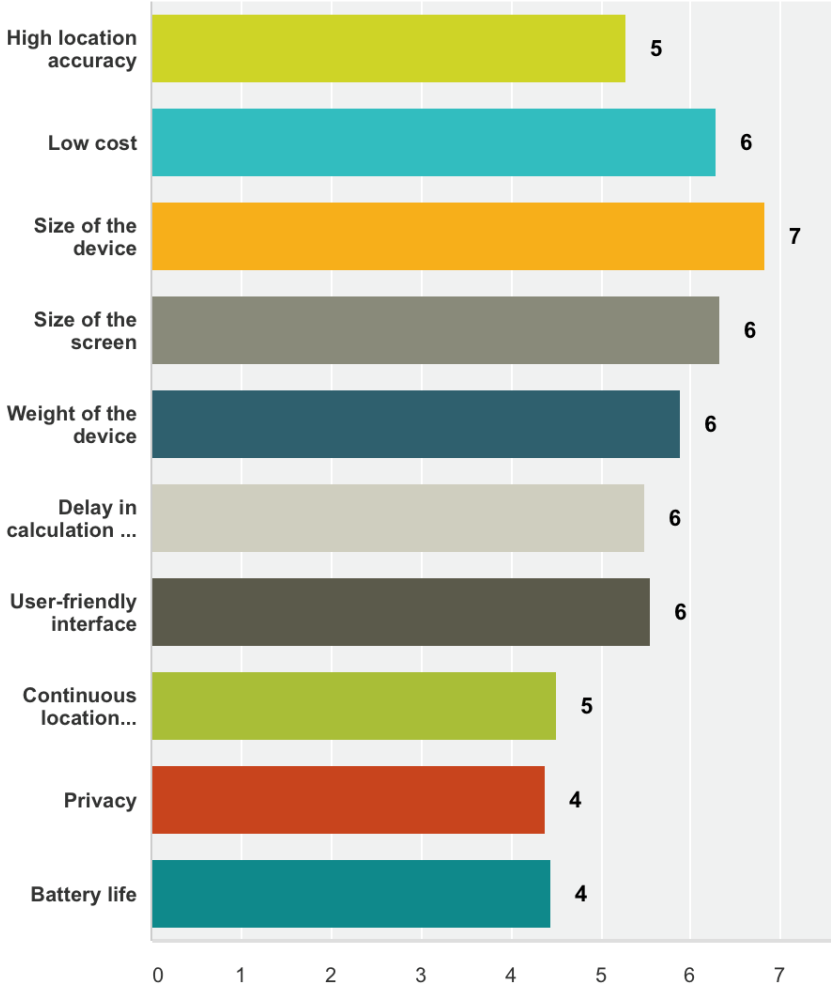

Fig. 2. The important features of location-enabled devices, such as SatNav and mobile phone, from users point of view (10 is the most important and 1 is the least)

As it is illustrated in figure 4, users prioritised the features of an app as following; privacy protection features, low power consumption, user-friendly interface, price of the first purchase and, the least importantly among others, subscription/update fee.

The very same question is asked from the app developers; excluding the cost of the device/hardware, the LBS app developers find the privacy and power consumption as the least important features of an LBS app to develop. Understandably, what they are interested in the most is the first purchase price. And the second important feature an LBS app they consider is the user-friendly interface, see figure 5.

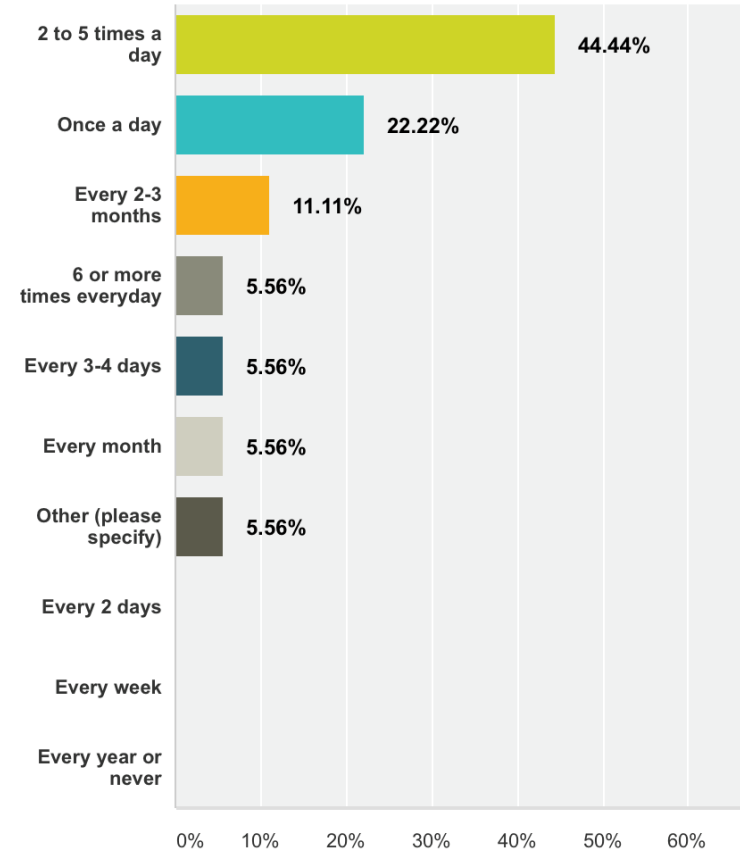

Fig. 3. The frequency of use of the LBS apps by LBS users

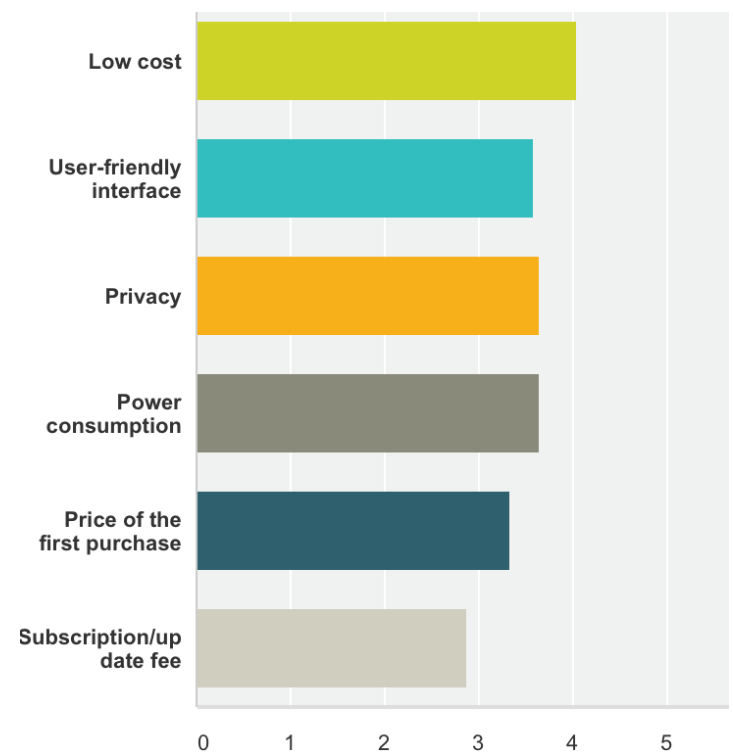

Fig. 4. The importance of LBS app features from LBS users point of view (10 is the most important and 1 is the least)

This wide gap between the concerns of LBS users and priorities of the LBS app developers to develop an app is one of the key challenges. The LBS users are willing to pay for the app and even more flexible to pay for the update of it, however their main concerns are privacy and power consumption. While app developers consider these two features, i.e. power and privacy, the least important features. 


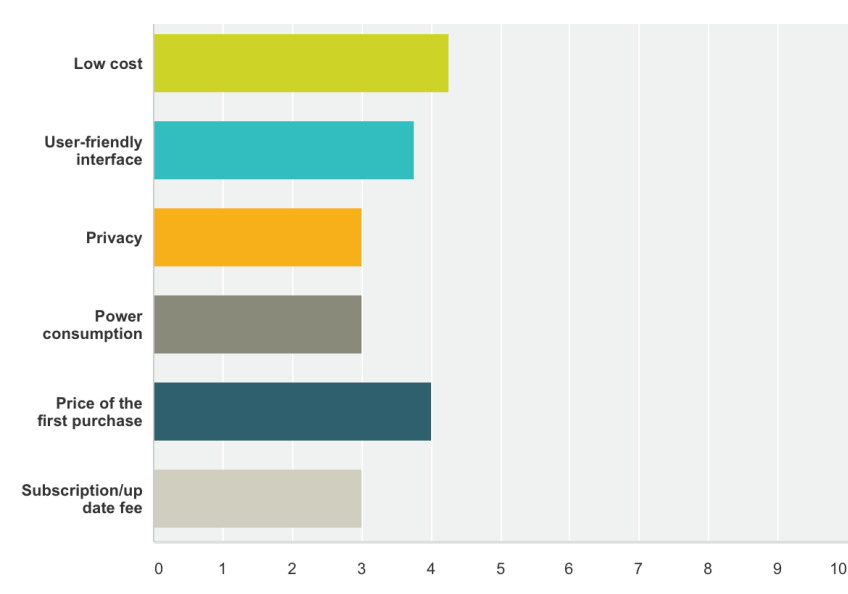

Fig. 5. The importance of LBS app features from LBS app developers' point of view (10 is the most important and 1 is the least)

Surprisingly, this gap, between what users want and what app developers are interested in, is not due to lack of mutual understanding between them. When the app developers are asked what the most important feature of a successful LBS app, they give fairly high rank to the privacy (on average 7.25 from 10), see figure 6. Giving equally importance level to the availability of the positioning service and the privacy reflects that the developers are fully aware of the significance of privacy concerns in the success or failure of an LBS app. However due to the lack of executable, enforcing and up-todate policies and regulations [10], lack of technical solutions [11], and lack of business models and monetisation schemes that do not push/require the developers to share the location data for advertisements purposes, the privacy of do not take as serious as it should be [12].

The LBS users seem to be happy to share their location (about $60 \%$ ) if the use of the data is clear for them. However in many cases there is a fear of re-/misuse of their location, in particular for distracting with advertisement services. The users change the location settings of the app if they feel that the app does not require their location to provide that particular service. Some of the answers include:

\section{...It depends on the service, if navigation or even tracking I don't mind changing the location/positioning settings...}

\section{...I always change the location privacy settings where the app necessarily doesn't need to have my location. I don't know why, for instance my dictionary requests my position...}

The very same question was answered by the developers, researchers, LBS content/technology providers very differently. It seems that becoming more aware of the potential threats, you would like to protect the privacy more strictly.

\begin{tabular}{|c|c|c|c|c|c|}
\hline v & Minimum & Maximum & Median & Mean & $\begin{array}{l}\text { Standard } \\
\text { Deviation }\end{array}$ \\
\hline $\begin{array}{l}\text { Novelty of the } \\
\text { idea behind the } \\
\text { app }\end{array}$ & 7.00 & 13.00 & 8.00 & 9.00 & 2.45 \\
\hline $\begin{array}{l}\text { Availability of } \\
\text { required APIs }\end{array}$ & 3.00 & 13.00 & 9.50 & 8.75 & 4.38 \\
\hline $\begin{array}{l}\text { Scalability } \\
\text { (request/user } \\
\text { number) }\end{array}$ & 5.00 & 11.00 & 7.50 & 7.75 & 2.38 \\
\hline $\begin{array}{l}\text { Loyalty to } \\
\text { previous } \\
\text { versions of } \\
\text { applications } \\
\text { and/or OS }\end{array}$ & 1.00 & 12.00 & 8.50 & 7.50 & 4.72 \\
\hline $\begin{array}{l}\text { User-friendly } \\
\text { interface }\end{array}$ & 5.00 & 9.00 & 8.00 & 7.50 & 1.50 \\
\hline $\begin{array}{l}\text { Monetisation } \\
\text { approach }\end{array}$ & 3.00 & 11.00 & 7.50 & 7.25 & 3.77 \\
\hline $\begin{array}{l}\text { Positioning } \\
\text { services } \\
\text { availability }\end{array}$ & 4.00 & 11.00 & 7.00 & 7.25 & 2.59 \\
\hline $\begin{array}{l}\text { Privacy } \\
\text { concerns }\end{array}$ & 2.00 & 13.00 & 7.00 & 7.25 & 5.26 \\
\hline $\begin{array}{l}\text { Positioning } \\
\text { capability of the } \\
\text { device/platform }\end{array}$ & 4.00 & 10.00 & 5.50 & 6.25 & 2.49 \\
\hline $\begin{array}{l}\text { Performance } \\
\text { (response time, } \\
\text { reusability } \\
\text { adaptability) }\end{array}$ & 3.00 & 9.00 & 6.50 & 6.25 & 2.17 \\
\hline $\begin{array}{l}\text { Accuracy and } \\
\text { validity of input } \\
\text { data (map, } \\
\text { content...) }\end{array}$ & 1.00 & 12.00 & 5.50 & 6.00 & 5.05 \\
\hline
\end{tabular}

Fig. 6. The ranking of the features contributing to thr success of an LBS app from LBS application developers' point of view

This has been also echoed by the researchers and participants from the companies; It seems that researchers and even market analysts overestimates the importance of price while they have a milder view on the importance of privacy, in comparison with the developers, see figure 7 . This has been also identified that the price becomes more important when you have deeper knowledge of IT, LBS, positioning and mobile applications [13].

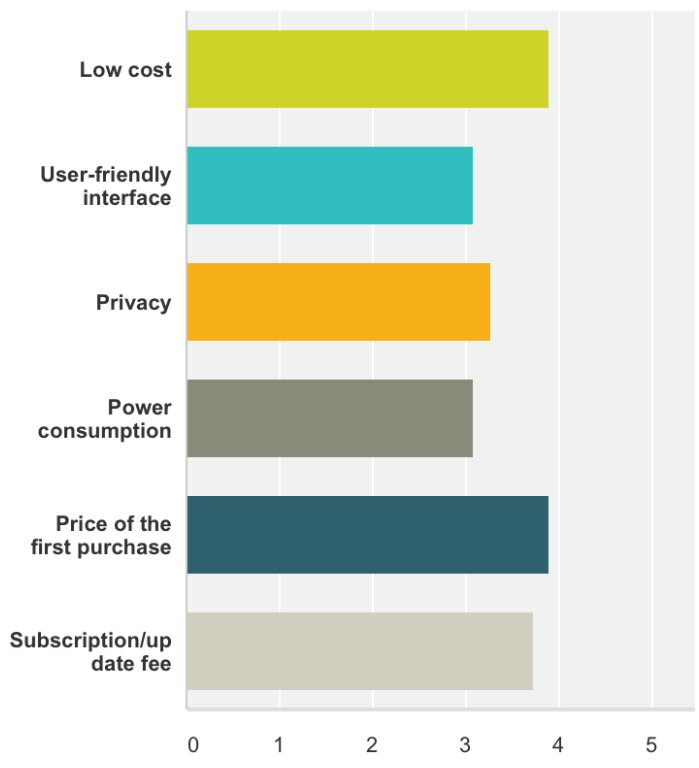

Fig. 7. The importance of LBS app features from researchers and marker analysts point of view (10 is the most important and 1 is the least) 
The study has also showed that the ordinary users view on privacy has become more relaxed, with respect to earlier years of mobile devices and apps, however there are still several concerns being shared by many users. This milder view on the threats of bridging their privacy might be due of the wider adoption of social media and location based social networking services, and the publicity of the success and the achievements of open source contributory projects such as OpenStreetMap [14].

\section{CONCLUSION}

This paper reviewed the non-technical challenges of LBS, including user interface, privacy, power consumption, first purchase fee, and subscription/update fee. A survey was conducted to understand the importance of these features for several target groups, including end-users, app developers, industry and researchers. The conducted survey, shows that the society view on privacy concerns has become milder over last years, however there are still several concerns being shared by many users. There are still big challenges remaining, which need new policies, techniques and architectures; as the survey showed that the developers are aware of the priority and concerns of end-users regarding their privacy but due to lack of legislations and policies the shortterm income scarifies the privacy of the users.

\section{ACKNOWLEDGMENT}

This work was financially supported by EU FP7 Marie Curie Initial Training Network MULTI-POS (Multi-technology Positioning Professionals) under grant nr. 316528.

\section{REFERENCES}

[1] Research and MarketsLBS Market in Southeast Asia CAGR Growth of $48.33 \%$ by 2020 - Analysis, Trends \& Opportunities Report 2016-2020, [Online], Available: http://www.researchandmarkets.com/research/gw4c6t/lbs_marke $\mathrm{t}$ in [Accessed: 22-February-2016].

[2] Marketsandmarkets, "Location Based Services (LBS) and RealTime Location Systems (RTLS) Market by Location (Indoor \& Outdoor), Technology (context-aware, UWB, BT/BLE, beacons, \& A-GPS, and others), Software, Hardware, Services, and Application Areas - Global Forecast to 2020", [Online]. Available: http://www.marketsandmarkets.com/MarketReports/location-based-service-market-96994431.html, [Accessed: 22-February-2016].

[3] Pew Research, "Location-based services, Smartphone Ownership 2013: Three-quarters of smartphone owners use location-based services (pew Internet \& American Life Project, 2013.

[4] GSA, "GNSS Market Report," 4th Edition, European GNSS Agency, 2015.

[5] A. Basiri, T. Moore, C. Hill, and P. Bhatia. "Challenges of Location-Based Services Market Analysis: Current Market
Description", Progress in Location-Based Services 2014, 273282, Springer Publishing, 2015.

[6] A. Basiri, P. Peltola, P. Silva, E. S. Lohan, C. Hill, and T. Moore "Indoor positioning technology assessment using analytic hierarchy process for pedestrian navigation services." In Localization and GNSS (ICL-GNSS), 2015 International Conference on, pp. 1-6. IEEE, 2015.

[7] A. Basiri, P. Silva, P. Peltola, E. S. Lohan, C. Hill, and T. Moore. "Overview of positioning technologies from fitness-topurpose point of view" In Localization and GNSS (ICL-GNSS), 2014 International Conference on, pp. 1-7. IEEE, 2014.

[8] R.B. Krishnan, N.H. Prasad, U. Gokul, P. Subashini, U.G. Scholar. Privacy Preserving Location Based Services. International Journal of Engineering Science, 2016. 2710.

[9] A. Baniukevic, S.C. Jensen, H. Lu. "Hybrid indoor positioning with Wi-Fi and Bluetooth: Architecture and performance." Mobile Data Management (MDM), 2013 IEEE 14th International Conference on. Vol. 1. IEEE, 2013.

[10] Why have almost all LBS apps failed?, available: https://www.quora.com/Why-have-almost-all-location-basedmessaging-apps-failed [Accessed: 12-March-2016].

[11] Why Do Mobile Apps Fail, Available: http://insights.wired.com/profiles/blogs/why-do-appsfail\#axzz42ner71qZ [Accessed: 12-March-2016].

[12] R. Abbas, K. Michael , MG. Michael, "The regulatory considerations and ethical dilemmas of location-based services (LBS) A literature review". Information Technology \& People. 2014. $25 ; 27(1): 2-0$.

[13] G. Daniel, D. Johansson, K. Andersson, and R. Brännström, "A case study of application development for mobile and locationbased services." In Proceedings of International Conference on Information Integration and Web-based Applications \& Services, p. 658. ACM, 2013.

[14] M. Pelka and H. Hellbrück. "Survey of Challenges and towards a unified Architecture for Location Systems." Journal of Network and Computer Applications (2016).

[15] T. Schmiedel, and JV. Brocke. "Business process management: Potentials and challenges of driving innovation." In BPMDriving Innovation in a Digital World, pp. 3-15. Springer International Publishing, 2015.

[16] M. Wernke, P. Skvortsov, F. Dürr, and K. Rothermel. "A classification of location privacy attacks and approaches". Personal and Ubiquitous Computing, 2014, 18(1), 163-175.

[17] R. Shokri. "Quantifying and protecting location privacy". itInformation Technology, 2015. 57(4), 257-263.

[18] J. Freudiger, R. Shokri, and JP. Hubaux. "Evaluating the privacy risk of location-based services". In Financial Cryptography and Data Security (pp. 31-46). 2012. Springer Berlin Heidelberg.

[19] D. Skoumetou, G. Seco-Granados, and E. S. Lohan, "User perception on Location Based Services: The more you know, the less you are willing to pay?," in International Conference on Localization and GNSS 2014 (ICL-GNSS 2014), 2014, pp. 1-6.

[20] L. Li, and MF. Goodchild. "Is privacy still an issue in the era of big data?-Location disclosure in spatial footprints." In Geoinformatics (GEOINFORMATICS), 2013 21st International Conference on, pp. 1-4. IEEE, 2013. 